\title{
Compassion-focused imagery reduces shame and is moderated by shame, self-reassurance and multisensory imagery vividness
}

\author{
Iona Naismith, Camilo Duran Ferro, Gordon Ingram, William Jimenez Leal \\ University of Los Andes, Colombia
}

\begin{abstract}
Compassion-focused imagery (CFI) is an emotion-regulation technique involving visualization of a person, animal or object offering one compassion, to generate feelings of safeness. It is proven to increase self-compassion and reduce negative affect. This study explores two hypotheses not previously investigated: i) which sensory modalities can stimulate compassionate affect; and ii) whether presentation of pictorial stimuli can enhance CFI. Additionally, we examine iii) whether CFI can reduce shame and iv) whether self-criticism inhibits CFI, since previous studies have involved small samples or methodological limitations. After completing measures of self-criticism, selfreassurance and imagery abilities in five sensory modalities, participants $(n=160)$ were randomly assigned to look at compassionate images during CFI (visual input), compassionate images before CFI (priming), or abstract images (control). Participants trialled CFI then rated compassionate affect and completed open-response questions. Before and after CFI, participants recalled a shame-based memory and rated state shame. Correlational analyses explored whether self-criticism, self-reassurance, and multisensory imagery abilities moderated outcomes. CFI significantly reduced shame regarding a recalled memory, particularly for those high in shame. Compassionate affect was predicted by imagery vividness in visual and bodily-sensation modalities. Self-criticism predicted poorer CFI In multiple regressions, self-reassurance predicted poorer CFI outcomes but self-criticism did not. Between-group effects did not emerge. Qualitative data suggested that pictures helped some participants but hindered others. CFI is a promising technique for shame-prone clients, but may be challenging for those with low imagery abilities or unfamiliar with self-reassurance. Multiple senses should be engaged.
\end{abstract}

Key words: Imagery; Compassion; Positive affect; Emotion; Self-criticism; Shame.

Correspondence: Iona Naismith, University of Los Andes, Colombia.

E-mail: ij.naismith@uniandes.edu.co

Citation: Naismith, I., Duran Ferro, C., Ingram, G., \& Jimenez Leal, W. (2019). Compassion-focused imagery reduces shame and is moderated by shame, self-reassurance and multisensory imagery vividness. Research in Psychotherapy: Psychopathology, Process and Outcome, 22(1), 113-122. doi: 10.4081/ripppo.2019.329

See online Appendix for additional material.

Contributions: IN conceived and planned the experiment and drafted the manuscript; IN and WJL analysed the data; all authors contributed to data collection and manuscript revision.

Conflict of interest: the authors declare no potential conflict of interest.

Funding: funding for the present study was provided by the University of Los Andes, Colombia.

Received for publication: 3 August 2018.

Accepted for publication: 7 November 2018.

This work is licensed under a Creative Commons Attribution NonCommercial 4.0 License (CC BY-NC 4.0).

CCopyright I. Naismith et al., 2019

Licensee PAGEPress, Italy

Research in Psychotherapy:

Psychopathology, Process and Outcome 2019; 22:113-122

doi:10.4081/ripppo.2019.329

\section{Introduction}

Mental imagery involves activation of perceptual information from memory, leading to an experience that has been described as "seeing with the mind's eye, hearing with the mind's ear, and so on" (Kosslyn, Ganis, \& Thompson, 2001, p. 635). Imagery can occur in any of the sensory modalities, including visual, auditory, olfactory, taste, touch, bodily sensation, and emotional feeling (Andrade, May, Deeprose, Baugh \& Ganis, 2014). A range of psychotherapeutic interventions aim to manipulate affect through modifying negative images or developing positive images (Holmes \& Mathews, 2010). These are grounded in evidence that mental images can evoke strong positive and negative affect: they can activate the amygdala (Kreiman, Koch, \& Fried, 2000), and elicit greater positive and negative affect than verbal information (Holmes, Coughtrey \& Connor, 2008; Holmes \& Mathew, 2005). Imagery can evoke emotion in several ways, including sensory signals directly influencing emotional signals, and images activating memories which then trigger emotions (Holmes \& Mathews, 2010).

\section{Compassion-focused imagery}

Compassion-focused therapy (CFT) was born from the idea that threat-based emotions such as anxiety and shame can be regulated by activating affiliation-based emotional networks (Gilbert, 2014). This network is acti- 
vated in children by parental warmth and affection in the context of a secure attachment relationship (Bowlby, 1969) motivates mammals to seek proximity to caregivers when threatened (Porges, 2007). CFT aims to help people develop emotion-regulation through activation of this soothing system. It can involve compassion for oneself, for others, or from others, with compassion defined as "a sensitivity to suffering... with a commitment to try to alleviate and prevent it" (Gilbert, 2014, p. 19).

One technique is compassion-focused imagery (CFI), which involves visualizing compassion towards others, or imagining people, places or objects directing compassion towards themselves (Gilbert, 2010). Single trials in nonclinical populations have reduced negative emotion, increase self-esteem, and produce physiological changes associated with attenuation of threat-defensive behaviours (Lincoln, Hohenhaus, \& Hartmann, 2013; Rockliff, Gilbert, McEwan, Lightman, \& Glover, 2008). Regular CFI practice has increased self-compassion in clinical and non-clinical populations (McEwan \& Gilbert, 2016; Naismith, Mwale, \& Feigenbaum, 2018). However, negative reactions can occur in clinical populations (Duarte et al., 2015).

\section{Moderators of compassion-focused imagery}

Improved understanding of factors that moderate CFI efficacy could enhance outcomes of compassion-based therapies, by identifying whether clients will benefit from standard interventions or need additional therapeutic work first.

Self-criticism and self-reassurance are the mostly commonly hypothesized inhibitors of compassion techniques. Gilbert, Baldwin, Irons, Baccus, and Palmer (2006) found that both were correlated with vividness of self-reassuring imagery and ease of imagining in 197 students; however, they did not measure affect generated by imagery (the most important outcome clinically). Duarte et al. (2015) found that high self-critics (HSCs) felt unsafe and experienced threat-like physiological reactions to imagery, concluding that CFI needs to include "interventions that manage fears, blocks, and resistances to the techniques, particularly in HSCs". However, the sample was small $(\mathrm{n}=25)$ and the threat-like physiological response seen was not specific to compassion techniques but also occurred whilst imagining relaxing scenery. Other studies have not replicated this effect: Rockliff et al. (2008) caution that high self-criticism may inhibit compassion generation in single trials of CFI (using heart-rate variability as the outcome), although results did not reach significance in a sample of 184 students. Naismith, Mwale, and Feigenbaum (2018) found that neither self-criticism nor self-reassurance predicted CFI outcomes in 53 clients with personality disorder.

Studies of multi-session CFI in sub- or non-clinical populations find conflicting evidence of these moderators: some find that high self-critics show greater improvement than low self-critics, which may reflect a floor effect in low self-critics (Kelly et al., 2010; McEwan \& Gilbert, 2016). However, Kelly et al. (2009) found that in a sample of 75, self-criticism was not a significant predictor of change in shame or depression following CFI. Overall, further research with large samples and valid outcome measures is important to establish whether these traits moderate CFI outcomes and whether all individuals can benefit from CFI.

Low imagery vividness (i.e., the image's resemblance to actual perceptual experience) across various imagery tasks was associated with reduced compassionate affect during CFI for clients with personality disorder (Naismith, Mwale, \& Feigenbaum, 2018). A qualitative study of the same sample found that several participants reported "just blankness" even after one week of practice (Naismith, Mwale, \& Feigenbaum, 2018). Kelly et al. (2010) found that imagery vividness predicted behaviour change in two of three imagery-based interventions for smoking reduction, including CFI.

Together, these findings suggest a possible avenue to increase CFI efficacy through increasing imagery vividness. Baddeley and Andrade (2000) proposed that imagery vividness depends on one's ability to store and manipulate sensory detail in working memory, influenced by several factors including available perceptual information, stored knowledge, working-memory capacity, executive processes involved in information retrieval and manipulation, and complexity of the imagined stimulus. Furthermore, mental imagery relies on many neural regions used for perception in the same modality: for example, both imagining and perceiving faces activate the fusiform face area (O'Craven \& Kanwisher, 2000). Furthermore, performance on imagery tasks correlates with early visual cortex activation (Cui, Jeter, Yang, ReadMontague, \& Eagleman, 2007). Since imagery vividness appears to moderate CFI efficacy, identifying ways to manipulate vividness is clinically important. One way to increase affect during imagery is by manipulating perspective: Holmes, Coughtrey, and Connor (2008) found that greater positive affect was induced by imagining events from first-person field perspective than from third-person observer perspective.

Secondly, CFI may be enhanced when it prompts sensory modalities that generate higher imagery vividness. Typically, visual and tactile imagery are most easily visualized, followed by sounds, bodily sensations (e.g. pain or body movements) and feelings (e.g. excitement), whilst taste and smell are hardest (Andrade et al., 2014). However, another consideration is which imagery modalities trigger stronger affect. Smells trigger memories with greater emotional intensity than visual, tactile or auditory stimulation (Herz, 1998), although it has not been established whether this applies to olfactory imagery.

We propose a third method to enhance CFI: presentation of sensory stimuli. Imagery can be created by recalling information stored in long-term memory (LTM), such 
as the melody of a song from childhood. Alternatively, it can be created by representing current sensory input in working memory, for example, looking at a painting and then visualizing it with eyes closed (Pearson, Deeprose, Wallace-Hadrill, Heyes, \& Holmes, 2013). Stored perceptual information is often combined or modified into novel representations. Thus, sensory cues might enhance CFI generation via two processes: by priming memories of compassion, or supplying sensory input. Priming might be especially helpful for individuals who cannot easily retrieve memories of compassion.

Alternatively, vivid CFI could be produced via directly reproducing pictures of compassion in working memory. Imagery from direct sensory input preserves surface characteristics of perceived stimuli (e.g., colours) more accurately than visual imagery generated from LTM (Cornoldi, De Beni, Guisberti, \& Massironi, 1998; Pearson \& Logie, 2004), but only if stimuli are continually present, reflecting the rapid decay of information in working memory. Direct sensory input could enhance CFI; alternatively, it could be less effective than LTM-generated compassionate imagery by producing a less elaborated and personally-relevant scene. Babin and Burns (1997) found no significant differences on imagery vividness when comparing imagery generated from viewing pictures, compared to a verbal description combined with instructions to imagine. To our knowledge, no study has yet evaluated whether sensory cues influence emotion generation through mental imagery. Finally, negative affect predicted poorer CFI outcomes in a clinical population (Naismith, Mwale, \& Feigenbaum, 2018). This variable was included in the present study to try to replicate that finding.

\section{The present study}

This study explores the efficacy of CFI and various hypothesized moderators. Firstly, we hypothesize that:

H1. Presentation of compassionate pictures before CFI (priming) and/or during CFI (continuous sensory input) will produce better CFI outcomes than a control group exposed to neutral images.

Shame is a key target of compassion-based techniques, yet very few studies have used this as an outcome variable (Kirby, Tellegen, \& Steindl, 2015). One exception found a reduction in shame following a CFI intervention for acne-sufferers (Kelly et al., 2009). Thus, the present study hypothesizes that:

$\mathrm{H} 2$. Shame regarding a recalled memory will reduce following CFI.

Based on considerations discussed previously, it is hypothesized that:

H3. Self-criticism, self-reassurance, shame, negative affect and effort during CFI will predict CFI outcomes.

H4. CFI outcomes will be predicted by imagery vividness in at least some of the five sensory modalities measured, including vision.

\section{Materials and Methods}

\section{Participants}

Participants were 160 psychology students from a private university in Bogotá, Colombia. Age ranged from 17 to 34 years $(\mathrm{M}=20.64, \mathrm{SD}=1.995)$. There were 114 females $(71.3 \%)$, and 44 males $(27.5 \%)$; one chose not to specify.

An a priori power analysis was run using $\mathrm{G}^{*}$ Power to identify the sample size required to detect a difference between three groups. Since no previous study has investigated the impact of pictorial stimuli on affect generated by mental imagery, we examined the sample size required to detect a medium effect size of $F=.25$ (on the basis that a small effect-size would be less clinically important). With $\alpha=.05$ and $\beta=.80$, a sample of $n=120$ was indicated as the minimum to detect such an effect. Following data collection, a sensitivity power analysis was run using the achieved sample size of $n=160$. With $\alpha=.05$ and $\beta=.80$, the analysis indicated that we can be reasonably confident that we would have identified an effect size of $F=.21$ or larger, had it existed.

\section{Materials}

Plymouth Sensory Imagery Questionnaire (PsiQ) (Andrade et al., 2014). The PsiQ consists of seven 5-item subscales measuring mental imagery in the sensory modalities of vision, sound, smell, taste, touch, bodily sensation, and emotional feelings. Participants are instructed to imagine various concepts, and rate imagery vividness from 0 (no image at all) to 10 (as vivid as real life). Test-retest reliability over 22 months was acceptable $(r=.71)$. The validated short version (three items per subscale) has high internal consistency ( $\alpha=.91$ to .94$)$, and subscale and total scores correlate highly with their full-scale counterparts, all $r>.89$ (Andrade et al., 2014). For this study, the short version was translated into Spanish with the recommended forward- and back-translation method. In the present sample, internal consistency of subscales was acceptable to good for all subscales $(\alpha=.69$ to .82$)$.

Forms of Self-Criticism/Attacking and Self-Reassuring Scale (FSCRS) (Gilbert et al., 2004). The FSCRS consists of 22 items rated on 5-point Likert scales, making up three components: self-inadequacy; self-hatred; and self-reassurance (ability to reassure oneself during difficulties). The original validation study found high internal consistency for all subscales ( $\alpha=0.86$ to 0.90 ). Factor analyses indicate that a three-factor model best fits the data; although self-inadequacy and self-hatred correlate highly, between $r=.68$ and .80 (Gilbert et al., 2004; Gilbert et al., 2010; Richter, Gilbert, \& McEwan, 2009). The present study used a validated Spanish translation of the scale (López-Cavada, Hornillos Cárdenas, \& López-Romero, 2017) which found moderate to high internal consistency for all subscales $(\alpha=.71$ to $\alpha=.88)$. 
Positive and Negative Affect Schedule (PANAS) (Watson, Clark, \& Tellegen, 1988). The PANAS measures positive and negative affect that participants feel in the present moment or the past week (two versions are available). Each item is scored from 1 (very slightly or not at all) to 5 (extremely). For this study we used the present moment version of the 10-item Negative Affect subscale, in its Spanish version; which has high internal consistency $(\alpha=0.88)$ and convergent validity with other mood measures (Robles \& Páez, 2003).

Vividness of CFI: This scale was developed for the present study. Participants rate vividness of CFI regarding five of the seven sensory modalities proposed in the PsiQ: vision, sound, touch, bodily sensation and smell. Taste was excluded (it was not deemed relevant for CFI), as was emotional feeling (since compassionate affect was measured in a separate multiple-item scale). Each item is rated on a Likert scale from 1 (No image at all) to 5 (as vivid as real life). In the present sample, internal consistency was acceptable $(\alpha=.71)$, and did not increase with any item removal.

Qualities of Compassion: This scale is based on the attributes that a compassionate image should have (wisdom; strength; warmth and kindness; dependability) according to the definition from Gilbert (2010). Participants rate to what extent their image has each attribute from 1 (none) to 5 (extremely). It has been used in a previous CFI study (Naismith, Mwale, \& Feigenbaum, 2018). Internal consistency was acceptable in the present study $(\alpha=.71)$; whilst it increased to .74 on removal of the 'wisdom' item, this was retained as the difference was small and the item deemed important for face validity.

Compassionate Affect: This scale was also developed for the present study, to measure compassionate affect generated by CFI. Four items were developed based on CFT literature (Gilbert, 2010; 2014) and designed to tap into emotions rather than concepts that confound emotions and thoughts. These were: 'I felt calm', 'I felt relaxed', 'I felt safe', and 'I felt content', all rated on a Likert scale from 1 (very little or not at all) to 5 (extremely). In the present sample, internal consistency was good $(\alpha=.83)$, and did not increase with any item removal.

Induced Shame Scale. A 4-item scale was developed for this study to evaluate shame experienced in relation to a memory. This was adapted from the Experiences of Shame Scale (Andrews, Qian, \& Valentine, 2002), which assesses three dimensions of state shame: feelings, shamebased cognitions (worrying about what others think), and shame-related behaviours (avoidance/concealment). Participants were presented with four items, rated on Likert scales from 1 (very little or not at all) to 5 (extremely): 'To what extent do you feel ashamed of the experience?' (feeling), 'Do you feel worried about what others think of you regarding this experience?'(cognition), 'To what extent do you want to avoid thinking about this experience?' and 'To what extent would you like to hide this experience from others?' (behaviours). In the present sample, internal consistency was good both pre- and post-CFI ( $\alpha=.80$ to $.85)$ and did not increase with item removal.

\section{Design}

Participants were randomly assigned to one of three groups: Group 1 (priming via exposure to compassionate pictures before CFI, $\mathrm{n}=50$ ), Group 2 (visual input via exposure to compassionate pictures before and during CFI, $\mathrm{n}=51$ ), or Group 3 (control: exposure to unrelated abstract images before CFI, $n=59$ ). A between-subject design was chosen since a repeated-measures design would be vulnerable to practice effects of CFI. The outcome variables were CFI vividness, compassionate affect, and qualities of compassion, as used in previous studies (Duarte et al., 2015; Kelly et al., 2010, Naismith, Mwale, $\&$ Feigenbaum, 2018), and change in shame from preto post-CFI.

\section{Procedure}

Ethical approval was obtained from Universidad de Los Andes. All procedures were in accordance with international ethical standards of human experimentation and with the Helsinki Declaration of 1975 (World Medical Association, 2013).

Data was collected after university lectures in four testing sessions, ranging from $n=13$ to $n=66$. Within each session, participants were randomly assigned to different conditions via which questionnaire pack they were given. Participants completed questions on age, sex, and the PsiQ, FSCSR, and PANAS (negative subscale), in that order. They were read a description of mental imagery, explaining that imagery can be multisensory, that sensory impressions in mental imagery tend to be fleeting, and that a wandering mind should be managed by noting this and gently returning their attention to the task. Participants were then read instructions adapted from a shame manipulation conducted in another student population (Berntsen \& Rubin, 2006), asking them to recall an experience during the past year in which they felt ashamed (see Appendix). They then completed the Induced Shame Scale.

Next, participants were read a definition of compassion and compassionate imagery techniques from Gilbert (2010), and an explanation of possible benefits. They were asked to follow the instructions on the final pages of their questionnaire booklets, which contained different pictures and instructions according to the three conditions. Participants in the Visual cue and Priming conditions were shown 12 colour photos: four parent-child relationships, four friendships, and four of caring for someone in need. They involved humans that varied in age, sex and ethnicity, and animals. Images highlighting illness, suffering or disability were avoided to prevent triggering sadness or thoughts of being undeserving. To increase cognitive processing of the compassionate images, participants in these 
conditions were asked to circle two images which they felt best represented compassion. The Visual cue condition prompted participants to continue examining these every 5-10 seconds throughout the upcoming imagery exercise to reduce image decay, whereas the Priming condition prompted participants to set aside these images during the imagery and focus on their mental image. In the Control condition, participants received 12 abstract shapes and were asked to circle the two images they were "most drawn to".

All participants were guided through a CFI exercise based on Creating a Compassionate Ideal from the CFT manual (Gilbert, 2010). CFI was preceded by brief relaxing-breathing following clinical guidelines (McEwan \& Gilbert, 2016). Participants were prompted to imagine from a first-person perspective, since this enhances affect change (Holmes, Coughtrey \& Connor, 2008). The original script prompts visual, auditory and emotional imagery; therefore, we added prompts for three other modalities: Smell, Touch, and Bodily sensation (see Appendix for details of the text used). Participants were asked to rate effort during the exercise from 1 ("did not try at all") to 10 ("tried my hardest").

Subsequently, participants completed the Vividness of CFI, Qualities of Compassion, and Compassionate Affect scales. Participants in the Priming and Visual Cue conditions were also asked the extent to which they had used: i) ideas/concepts or ii) specific visual features from the photos to construct their mental image. Both were rated from 1 ("very little or not at all") to 5 ("extremely"). Qualitative data was collected by asking: 'If the photos were useful in any way, please explain here:'

Finally, participants were asked to recall the shamebased experience again, but this time bringing to mind the compassionate figure and considering its perspective regarding their past actions and current feelings, before again completing the Induced Shame Scale.

\section{Results}

Self-hatred and negative affect data underwent squareroot transformations to reduce positive skew. PsiQ data underwent squared transformation to reduce negative skew.

\section{H1. Use of pictorial cues will produce between-group differences on compassion-focused imagery outcomes}

ANOVAs indicated that the groups did not differ on age, self-reassurance, self-inadequacy, self-hatred, negative affect, imagery abilities (PsiQ total), visual imagery abilities (PsiQ visual subscale) nor effort on CFI ( $\mathrm{P}>.281$ ). A chi-squared analysis found no group differences regarding gender $(\mathrm{P}>$. 194). Descriptive statistics for these variables are given in Table 1.

ANOVAs found no significant differences between groups on CFI outcomes: CFI vividness $(F(2,156)=0.145$, $\mathrm{P}=.865)$, compassionate affect $(F(2,157)=1.074, \mathrm{P}=.344)$, and change in shame $(F(2,155)=0.441, \mathrm{P}=.644)$. Descriptive statistics are provided in Table 1. Groups 1 and 2 did not differ regarding the questions 'To what extent did you use ideas from the photos to construct your mental image?' $(\mathrm{P}=.964)$ and 'To what extent did you use specific visual features from the photos to construct your mental image?' $(\mathrm{P}=.151)$; therefore it is possible that many in group 2 (visual input) only attended to the pictures before CFI and thus essentially received priming only.

Whilst no significant group differences emerged, qualitative data from groups 1 and 2 suggested that some in-

Table 1. Descriptive statistics and between-group comparison P-values for hypothesized predictors and compassion-focused imagery outcome variables.

\begin{tabular}{llcccc}
\hline & & $\begin{array}{c}\text { Group 1 } \\
\text { (priming) }\end{array}$ & $\begin{array}{c}\text { Group 2 } \\
\text { (sensory input) }\end{array}$ & $\begin{array}{c}\text { Group 3 } \\
\text { (control) }\end{array}$ & \multicolumn{1}{c}{ P-value } \\
\hline $\mathrm{N}$ & & 51 & 50 & 59 & \\
\hline Gender & $\mathrm{N}$ female $(\%)$ & $39(76.5)$ & $32(64.0)$ & $43(72.9)$ & .194 \\
\hline Age & $\mathrm{M}(\mathrm{SD})$ & $20.31(1.78)$ & $20.74(1.85)$ & $20.75(2.48)$ & .347 \\
\hline Self-reassurance & $\mathrm{M}(\mathrm{SD})$ & $21.53(6.65)$ & $22.24(5.71)$ & $21.28(6.30)$ & .714 \\
\hline Self-inadequacy & $\mathrm{M}(\mathrm{SD})$ & $19.33(8.11)$ & $20.52(7.22)$ & $21.24(7.72)$ & .433 \\
\hline Self-hatred & $\mathrm{M}(\mathrm{SD})$ & $5.39(5.19)$ & $5.44(4.85)$ & $6.65(5.17)$ & .411 \\
\hline Negative affect & $\mathrm{M}(\mathrm{SD})$ & $19.04(6.68)$ & $19.04(6.68)$ & $17.31(2.55)$ & .644 \\
\hline Plymouth Sensory Imagery Questionnaire (PsiQ) total & $\mathrm{M}(\mathrm{SD})$ & $152.67(38.07)$ & $160.42(30.87)$ & $154.20(27.50)$ & .541 \\
\hline PsiQ vision & $\mathrm{M}(\mathrm{SD})$ & $24.79(4.64)$ & $24.85(4.06)$ & $23.30(4.75)$ & .302 \\
\hline Compassion-focused imagery vividness & $\mathrm{M}(\mathrm{SD})$ & $18.75(4.58)$ & $17.77(3.39)$ & $18.60(3.63)$ & .865 \\
\hline Compassionate affect & $\mathrm{M}(\mathrm{SD})$ & $16.58(3.67)$ & $16.38(4.57)$ & $17.24(2.60)$ & .344 \\
\hline Change in shame & $\mathrm{M}(\mathrm{SD})$ & $4.21(3.48)$ & $3.69(2.69)$ & $3.30(3.13)$ & .644 \\
\hline
\end{tabular}


dividuals found the images helpful, for a variety of reasons. When asked "If the compassionate images were useful, please explain why", 10 participants reported that the pictures helped by illustrating compassionate actions, gestures or facial expressions. For example: "[The pictures] helped me a lot to imagine actions such as hugging and smiling" and "The photos allowed me to imagine the actions that my compassionate figure would do, and how it would feel to be with her".

Nine reported that the images were helpful because they helped them to recall or conjure up a figure, noting "I thought about two situations from the images...one with a dog and one with a person helping someone in need." and "One image reminded me of my grandmother who is vulnerable, and I would like to be compassionate with her".

Five participants found the pictures to be helpful in providing a situation to imagine: "They helped to think of scenes from real life that I have experienced, which were similar to the photos" and "I imagined a situation like in the photos, but not with the same people or doing the same actions".

Four participants perceived the pictures to be helpful because they induced compassionate affect. They reported "They gave me feelings of warmth and tenderness and I could more easily express the feelings of compassion" and "I think that they were useful for feeling compassion, but not useful in creating the compassionate figure".

A proportion of participants offered explanations as to why the images were not helpful. In all cases, they indicated that the pictures did not represent what they wished to imagine, for example: "No, I was thinking about life experiences instead", "No because I imagined Jesus with me", and "I could not imagine a human figure. The verbal instructions gave the example of imagining a place, but in the photos there was no such example".

\section{H2. Shame will reduce following compassion-focused imagery}

As hypothesised, there was a significant decrease in shame regarding the recalled memory from pre-CFI $(M=13.81, S D=3.83)$ to post-CFI $(M=10.34, S D=3.94)$, $t(157)=-14.62, \mathrm{P}<.001, d=0.63$.
H3. Compassion-focused imagery will be predicted by self-criticism, self-reassurance, shame, negative affect and effort

Greater compassionate affect was produced in individuals with lower self-hatred, lower self-inadequacy, lower shame, lower negative affect, and higher self-reassurance $(\mathrm{P}<.023$, (Table 2). However, a multiple regression with these five predictors revealed that only self-reassurance $(\beta=-.223, \mathrm{P}=.034)$ and negative affect $(\beta=-.206, \mathrm{P}=.022)$ had unique predictive power. Overall, the model explained $14.3 \%$ of the variance $\left(\mathrm{R}^{2}=.143, F(5,146)=4,857, \mathrm{P}<.001\right)$.

Change in shame (pre-shame subtracted from postshame) was negatively correlated with pre-shame $(\mathrm{P}<.001)$, indicating that people higher in pre-shame experienced greater reduction in shame. Shame change was not correlated with self-hatred, self-inadequacy, self-reassurance or negative affect $(\mathrm{P}>$.434) (Table 2).

Effort ratings for the CFI exercise were relatively high $(\mathrm{M}=7.67, \mathrm{SD}=2.01)$. Self-reported effort during CFI strongly correlated with subsequent compassionate affect $(P>.001)$ and change in shame $(\mathrm{P}=.018)$, (Table 2$)$.

Correlations between hypothesized predictors were also examined. Pre-CFI shame correlated positively with selfinadequacy $(r=.306, \mathrm{P}<.001)$, self-hatred $(r=.196, \mathrm{P}=.013)$, and negative affect $(r=.279, \mathrm{P}=.001)$, and negatively with self-reassurance $(r=-.171, \mathrm{P}=.032)$.

\section{H4. Imagery vividness in some sensory modalities will predict compassion-focused imagery outcomes}

CFI vividness was strongest for the bodily sensation modality $(\mathrm{M}=4.23, \mathrm{SD}=0.94)$, followed by visual $(\mathrm{M}=4.01$, $\mathrm{SD}=0.98)$ and touch modalities $(\mathrm{M}=4.00, \mathrm{SD}=1.08)$, then auditory $(\mathrm{M}=3.40, \mathrm{SD}=1.30)$, and finally olfactory $(\mathrm{M}=2.73, \mathrm{SD}=1.36)$. In comparison, general imagery vividness (PsiQ) was strongest in the auditory modality $(\mathrm{M}=24.65, \mathrm{SD}=5.47)$, followed by visual $(\mathrm{M}=23.95$, $\mathrm{SD}=4.61)$, touch $(\mathrm{M}=23.49, \mathrm{SD}=5.88)$, bodily sensations $(\mathrm{M}=21.84, \mathrm{SD}=6.25)$, and finally olfactory $(\mathrm{M}=17.19$, $\mathrm{SD}=7.90)$. Across all groups, compassionate affect was predicted by total CFI vividness $(\mathrm{P}<.001)$; but only vividness in visual and bodily sensations modalities had unique pre-

Table 2. Correlation coefficients and P-values between outcomes (compassionate affect and change in shame) and hypothesized predictors.

\begin{tabular}{|c|c|c|c|c|c|c|c|}
\hline & & $\begin{array}{l}\text { Shame } \\
\text { pre-compassion- } \\
\text { focused imagery }\end{array}$ & Self-hatred & Self-inadequacy & Self-reassurance & Negative affect & Effort \\
\hline \multirow[t]{2}{*}{ Change in shame } & $r$ & $-.350 * *$ & -.066 & -.057 & .010 & -.030 & -.234 \\
\hline & $\mathrm{P}$ & $<.001$ & .413 & .480 & .902 & .718 & .018 \\
\hline \multirow[t]{2}{*}{ Compassion Affect } & $r$ & $-.180 *$ & $-.306 * *$ & $-.242 * *$ & $.289 * *$ & $-.306 * *$ & $.412 * *$ \\
\hline & $\mathrm{P}$ & .023 & $<.001$ & .002 & $<.001$ & $<.001$ & $<.001$ \\
\hline
\end{tabular}

$*$ Significant at $\alpha=.05 ; * *$ Significant at $\alpha=.01$. 
dictive power (Table 3 ). Overall, the model explained $31.7 \%$ of the variance $\left(\mathrm{R}^{2}=0.317, F(5,153)=14.231\right.$, $\mathrm{P}<.001)$.

The multiple regression was rerun in only the control group to examine which modalities predicted compassionate affect when participants were not exposed to compassionate pictures (which could bias the influence of the visual modality). Overall, the model explained $31.7 \%$ of the variance $\left(\mathrm{R}^{2}=0.317, F(5,52)=4.838, \mathrm{P}=.001\right)$. No individual predictors reached significance, but olfactory, bodily sensations, and auditory vividness approached significance (Table 3).

Change in shame was not correlated with CFI vividness across all groups, although the result was in the expected direction $(\mathrm{P}=.059)$.

Contrary to expectations, most of the Psi-Q subscales did not correlate with CFI vividness items for the respective modalities, including vividness of visual $(\mathrm{P}=.871)$, auditory $(\mathrm{P}=.641)$, and bodily sensation imagery $(P=.080)$. PsiQ olfactory and tactile subscales correlated significantly with the respective items for CFI vividness $(\mathrm{P}<.004)$, but also with other CFI vividness items.

\section{Discussion}

Key findings were: i) vividness strongly predicted generated affect; ii) pictorial stimuli did not enhance CFI for non-clinical populations; iii) CFI reduced shame; iv) selfcriticism was associated with poorer outcomes on CFI, but not after controlling for self-reassurance; and v) imagery in multiple sensory modalities generated compassionate affect.

\section{Imagery vividness predicted affect}

Vividness during CFI was more predictive of generated compassionate affect (31.7\%) than self-criticism, self-reassurance, shame, and negative affect combined (14.3\%). This corroborates previous findings that vividness is important for CFI outcomes (Naismith, Mwale, \& Feigenbaum, 2018).

\section{Pictorial cues did not enhance compassion-focused imagery for non-clinical groups}

For non-clinical groups, CFI was not enhanced by priming effects nor sensory input from compassionate pictorial cues. The power calculation indicated that we would have likely identified a small-to-medium effect size of $\mathrm{F}=.214$ or larger, had it existed. Thus, pictorial cues appeared to have little or no effect on outcomes in a nonclinical population. It remains to be determined whether sensory cues facilitate CFI in clinical populations that attribute difficulties in CFI to having few representations of compassion to draw from, such as personality disorder (Naismith, Mwale \& Feigenbaum, 2018). Qualitative data indicated that the most common benefit from the pictures was offering examples of compassionate actions, gestures or facial expressions.

Despite receiving different instructions, groups 1 and 2 did not differ in the extent to which they used the compassionate pictures, so the sensory input condition may not be internally valid. This may reflect participants' desire to draw on LTM representations of compassion that are more meaningful and affective.

\section{Compassion-focused imagery reduces shame}

As predicted, shame regarding a recalled experience was significantly lower when recall was preceded by CFI and the individual brought a compassionate figure to mind. This supports the use of CFI for psychological disorders with inflated shame, including social and generalized anxiety (Fergus, Valentiner, McGrath, \& Jencius, 2010), eating disorders (Frank, 1991), and some personality disorders (Ritter et al., 2014; Scheel et al., 2014).

\section{Self-reassurance, negative affect and shame predict compassion-focused imagery outcomes}

Greater compassionate affect was produced in individuals with higher self-reassurance, and lower self-inade-

Table 3. Vividness of compassion-focused imagery (CFI) in different modalities as predictors of compassionate affect (using multiple regressions).

\begin{tabular}{lllll}
\hline $\begin{array}{l}\text { Vividness of CFI } \\
\text { across modalities }\end{array}$ & & All participants & Group 1 \& 2 & Group 3 (control) \\
\hline Visual & $\beta$ & .237 & .337 & .073 \\
& $\mathrm{P}$ & .003 & .001 & .580 \\
\hline Auditory & $\beta$ & .115 & .077 & .207 \\
& $\mathrm{P}$ & 126 & .763 & .088 \\
\hline Tactile & $\beta$ & .066 & .074 & -.020 \\
& $\mathrm{P}$ & .490 & .649 & .915 \\
\hline Bodily sensations & $\beta$ & .255 & .246 & .357 \\
& $\mathrm{P}$ & .009 & .033 & .062 \\
\hline Olfactory & $\beta$ & .123 & .041 & .237 \\
& $\mathrm{P}$ & .108 & .682 & .060 \\
\hline
\end{tabular}


quacy, self-hatred, shame, and negative affect. However, only self-reassurance and negative affect had unique predictive power. Although the effect was not large, this indicates that CFI is more effective when individuals have developed some self-reassurance and are not experiencing strong negative affect, in accordance with studies of clinical populations (Naismith, Mwale \& Feigenbaum, 2018). Since self-criticism is not significant after controlling for self-reassurance, the primary barrier to CFI may not be a tendency to self-criticize but instead an unfamiliarity with self-compassion/reassurance. A likely reason is that such individuals have a lack of relational templates to draw from during CFI: low self-compassion is predicted by lack of warmth in childhood, but self-criticism is not (Naismith, Zarate Guerrero \& Feigenbaum, 2019). This supports the theory that threat-processes like self-criticism stem from a distinct neurobiological system to that underlying affiliative processes like self-compassion (Gilbert, 2015).

Greater reduction of shame following CFI occurred in those high in initial shame, which may reflect a floor effect in low-shame individuals. Shame reduction was not predicted by self-reassurance, self-criticism or negative affect. This is compatible with literature that states that reducing negative affect (e.g. shame) is a distinct but related process to increasing positive compassionate affect (Gilbert, 2014), and thus might have different inhibitors.

\section{Imagery in various modalities can generate compas- sionate affect}

PsiQ data indicated that across a range of scenes, participants experienced strongly vivid imagery in the auditory, visual and tactile modalities, and less vivid bodily sensation or olfactory imagery. In comparison, CFI was most vivid in bodily sensation imagery, then visual and tactile modalities. This reflects the role of visual and tactile stimuli for triggering the soothing system. Smiling (a visual stimulus) communicates non-threatening motives (Parkinson, 2005). Interpersonal touch, particularly from loved ones, reduces negative mood and activation of brain regions associated with threat-processing (Coan, Schaefer \& Davidson, 2006; Murphy, Janicki-Deverts \& Cohen, 2018). Indeed in Harlow's (1959) classic experiments, infant monkeys preferred a surrogate mother made of cloth to a wiremesh model, even when the latter delivered their food. In groups 1 and 2, only vividness of bodily sensations and visual imagery predicted compassionate affect generation. In the control group, olfactory, bodily sensation and auditory imagery only approached significance in the control group, which may reflect a lack of power. This suggests that exposure to compassionate pictures enhanced visual imagery but may have reduced participants' efforts in other modalities. CFI scripts should therefore include prompts for a range of modalities, particularly bodily sensations and vision, to maximise affect generation. Contrary to expectations, most Psi-Q subscales did not correlate with CFI vividness items for the respective modalities. This may be because the PsiQ reflects brief attempts to imagine whilst CFI involves extended imagery, which may make different cognitive demands.

\section{Strengths and limitations}

The relatively large sample enabled us to run regressions with multiple predictors and identify which factors had unique predictive power. A between-subjects design prevented the influence of practice effects between conditions; however, a within-subjects design would have enabled us to seek participants' views on whether the priming was a help or hindrance. Unlike most previous CFI studies, this study measured compassionate affect with a multi-item scale. Using shame as another outcome measure of CFI enabled us to examine changes in both positive and negative affect.

\section{Clinical implications}

The present study strengthens support for the use of CFI for individuals high in shame. High-shame individuals generated less compassionate affect but experienced greater reductions in shame than low-shame individuals. CFI scripts should include prompts for multiple sensory modalities. Visual cues did not significantly improve outcomes for non-clinical populations, but some individuals reported them to be helpful. It remains to be seen whether they help clinical populations that have weaker LTM representations of compassion.

\section{Future research}

A possible avenue of research is to explore whether videos with compassionate narratives and actions activate compassion emotions more than pictorial stimuli, since videos provide more information than pictures. However, additional information creates an increased cognitive load which reduces imagery vividness (Lilley, Andrade, Turpin, Sabin-Farrell, \& Holmes, 2009). Mental images generated from LTM are less vivid when they are dynamic rather than static (Baddeley \& Andrade, 2000), and viewing negatively-valenced pictures produces significantly more negative affect than film-clips do (Uhrig et al., 2016).

Photos of loved ones might enhance CFI more than unfamiliar figures. However, in the authors' clinical experience, recall of familiar figures can produce negative CFI experiences if the relationship has been difficult. Finally, cues from different sensory modalities that interfere less with LTM representations of compassion could be investigated, such as soothing smells or tactile sensations from a blanket.

\section{Conclusions}

The present study indicates that CFI is a promising emotion-regulation technique, particularly for shame- 
prone clients. Individuals unfamiliar with self-reassurance may require additional support, whilst those with weak imagery abilities may benefit more from other techniques. Clinicians should prompt multiple senses, especially visual, tactile and bodily-sensations, to maximize efficacy.

\section{References}

Andrade, J., May, J., Deeprose, C., Baugh, S.J., \& Ganis, G. (2014). Assessing vividness of mental imagery: The Plymouth Sensory Imagery Questionnaire. British Journal of Psychology, 105(4), 547-563. doi: 10.1111/bjop. 12050.

Andrews, B., Qian, M. Y., \& Valentine, J. D. (2002). Predicting depressive symptoms with a new measure of shame: The Experience of Shame Scale. British Journal of Clinical Psychology, 41, 29-42. doi: 10.1348/014466502163778

Babin, L.A., \& Burns, A.C. (1997). Effects of print ad pictures and copy containing instructions to imagine on mental imagery that mediates attitudes. Journal of Advertising, 26(3), 33-44.

Baddeley, A. D., \& Andrade, J. (2000). Working memory and the vividness of imagery. Journal of Experimental Psychology General, 129, 126-145. doi: 10.1037/0096-3445.129.1.126

Berntsen, D. \& Rubin, D.C. (2006) Emotion and vantage point in autobiographical memory. Cognition and Emotion, 20(8), 1193-1215. doi.org/10.1080/02699930500371190

Bowlby, J. (1969). Attachment: Attachment and loss (Vol. 1). London: Hogarth Press.

Coan, J. A., Schaefer, H. S., \& Davidson, R. J. (2006). Lending a hand: Social regulation of the neural response to threat. Psychological Science, 17(12), 1032-1039. doi: 10.1111/j.1467-9280.2006.01832.x.

Cornoldi C., De Beni R., Guisberti F., \& Massironi M. (1998). Memory and imagery: A visual trace is not a mental image. In: Conway M., Gathercole S., Cornoldi C. (Eds). Theories of memory (pp. 87-110). Psychology Press: Hove, UK.

Cui, X., Jeter, C.B., Yang, D., Read-Montague, P. \& Eagleman, D.M. (2007). Vividness of mental imagery: Individual variability can be measured objectively. Vision Research, 47(4), 474-478. doi: 10.1016/j.visres.2006.11.013

Duarte, J., McEwan, K., Barnes, C., Gilbert, P., \& Maratos, F. A. (2015). Do therapeutic imagery practices affect physiological and emotional indicators of threat in high self-critics? Psychology and Psychotherapy - Theory, Research and Practice, 88(3), 270-284. doi: 10.1111/papt.12043

Fergus, T. A, Valentiner, D. P., McGrath, P. B., \& Jencius, S. (2010). Shame- and guilt-proneness: Relationships with anxiety disorder symptoms in a clinical sample. Journal of Anxiety Disorders, 24(8), 811-815. doi: 10.1016/j.janxdis. 2010.06.002

Frank, E. S. (1991). Shame and guilt in eating disorders. American Journal of Orthopsychiatry, 61(2), 303-306. doi: $10.1037 / \mathrm{h} 0079241$

Gilbert, P. (2010). Training our minds in, with and for compassion. An introduction to concepts and compassion-focused exercises. Available from http://www.compassionatemind. co.uk/downloads/training_materials/3.\%20Clinical_patient_h andout.pdf

Gilbert, P. (2014). The origins and nature of compassion focused therapy. British Journal of Clinical Psychology, 53, 6-41. doi: 10.1111/bjc. 12043 .
Gilbert, P. (2015). Affiliative and prosocial motives and emotions in mental health. Dialogues in Clinical Neuroscience, 17, 381-389.

Gilbert, P., Baldwin, M. W., Irons, C., Baccus, J. R., \& Palmer, M. (2006). Self-Criticism and Self-Warmth: An Imagery Study Exploring Their Relation to Depression. Journal of Cognitive Psychotherapy, 20(2), 183-200. doi: 10.1891/jcop. 20.2.183.

Gilbert, P., Clarke, M., Hempel, S., Miles, J. N. V., \& Irons, C. (2004). Criticizing and reassuring oneself: An exploration of forms, styles and reasons in female students. British Journal of Clinical Psychology, 43(1), 31-50. doi: 10.1348/ 014466504772812959.

Harlow, H. (1958). The nature of love. American Psychologist, 13(12), 673-685. doi: 10.1037/h0047884.

Herz, R. (1998). Are odors the best cues to memory? A crossmodal comparison of associative memory stimuli. Annals of the New York Academy of Science, 30(855), 670-674.

Holmes, E. A., Coughtrey, A. E., \& Connor, A. (2008). Looking at or through rose-tinted glasses? Imagery perspective and positive mood. Emotion, 8(6): 875-9. doi: 10.1037/a0013617.

Holmes, E. A., \& Mathews, A. (2005). Mental imagery and emotion: A special relationship? Emotion, 5(4), 489-497. doi: 10.1037/1528-3542.5.4.489

Holmes, E. A., \& Mathews, A. (2010). Mental imagery in emotion and emotional disorders. Clinical Psychology Review, 30(3), 349-362. doi: 10.1016/j.cpr.2010.01.001.

Kelly, A. C., Zuroff, D. C., \& Shapira, L. B. (2009). Soothing oneself and resisting self-attacks: The treatment of two intrapersonal deficits in depression vulnerability. Cognitive Therapy and Research, 33(3), 301-313. doi: 0.1007/s10608008-9202-1.

Kelly, A. C., Zuroff, D. C., Foa, C. L., \& Gilbert, P. (2010). Who benefits from training in self-compassionate self-regulation? A study of smoking reduction. Journal of Social and Clinical Psychology, 29(7), 727-755. doi: 10.1521/jscp.2010.29.7.727

Kirby, J., Tellegen, C. L., \& Steindl, S. R. (2015). A meta-analysis of compassion-based interventions: current state of knowledge and future directions. Behavior Therapy, 48, 778-792. doi: 10.1016/j.beth.2017.06.003

Kreiman, G., Koch, C. \& Fried, I. (2000). Imagery neurons in the human brain. Nature, 408, 357-361. doi: 10.1038/35042575

Kosslyn, S.M. (1994). Image and brain: The resolution of the imagery debate. MIT Press: Cambridge, MA.

Kosslyn, S. M., Ganis, G., \& Thompson, W. L. (2001). Neural foundations of imagery. Nature Reviews Neuroscience, 2(9):635-642.

Lilley, S. A., Andrade, J., Turpin, G., Sabin-Farrell, R., \& Holmes, E. A. (2009). Visuospatial working memory interference with recollections of trauma. British Journal of Clinical Psychology, 48(3), 309-321. doi: 10.1348/014466508X398943.

Lincoln, T. M., Hohenhaus, F., \& Hartmann, M. (2013). Can paranoid thoughts be reduced by targeting negative emotions and self-esteem? An experimental investigation of a brief compassion-focused intervention. Cognitive Therapy and Research, 37(2), 390-402. doi: 10.1007/s10608-012-9470-7

López Cavada, C., Hornillos Cárdenas, T., \& López-Romero, H. Y. (2017). Self-criticism: measure and Treatment. Paper presented at the International Society for Emotion Focused Therapy (ISEFT), Toronto.

McEwan, K. \& Gilbert, P. (2016), A pilot feasibility study exploring the practising of compassionate imagery exercises in a nonclinical population. Psychology and Psychotherapy: 
Theory, Research and Practice, 89, 239-243. doi: 10.1111/papt.12078

Murphy, M.L.M., Janicki-Deverts, D., \& Cohen, S. (2018) Receiving a hug is associated with the attenuation of negative mood that occurs on days with interpersonal conflict. PLoS ONE, 13(10), e0203522.

Naismith, I., Mwale, A. \& Feigenbaum, J. (2018). Inhibitors and facilitators of compassion-focused imagery in personality disorder. Clinical Psychology and Psychotherapy, 25(2):283-291. doi: 10.1002/cpp.2161.

Naismith, I., Zarate Guerrero, S., \& Feigenbaum, J. (2019). Abuse, invalidation, and lack of early warmth show distinct relationships with self-criticism, self-compassion, and fear of self-compassion in personality disorder. Clinical Psychology \& Psychotherapy. [Advance online publication]. doi: 10.1002/cpp.2357.

O'Craven, K. M. \& Kanwisher, N. (2000). Mental imagery of faces and places activates corresponding stimulus-specific brain regions. Journal of Cognitive Neuroscience, 12, 10131023.

Parkinson, B. (2005). Do facial movements express emotions or communicate motives? Personality and Social Psychology Review, 9(4), 278-311. doi: 10.1207/s15327957pspr0904_1.

Pearson, D. G., Deeprose, C., Wallace-Hadrill, S. M. A., Heyes, S. B., \& Holmes, E. A. (2013). Assessing mental imagery in clinical psychology: A review of imagery measures and a guiding framework. Clinical Psychology Review, 33(1), 123. doi: 10.1016/j.cpr.2012.09.001

Pearson D. G. \& Logie R. H. (2004). Effects of stimulus modality and working memory load on mental synthesis performance. Imagination, Cognition, and Personality, 23(2-3):183-192. doi: 10.2190/KRQB-0CED-NX6J-HQ72

Porges, S. W. (2007). The polyvagal perspective. Biological Psychology, 74, 116-143. doi: 10.1016/j.biopsycho.2006.06.009.

Richter, A., Gilbert, P., \& McEwan, K. (2009). Development of an early memories of warmth and safeness scale and its relationship to psychopathology. Psychology and Psychotherapy: Theory, Research and Practice, 82(2), 171-184. doi: 10.1348/147608308X395213.

Ritter, K., Vater, A., Rüsch, N., Schröder-Abé, M., Schütz, A., Fydrich, T., Lammers, C.H., \& Roepke, S. (2014) Shame in patients with narcissistic personality disorder. Psychiatry Research, 215(2), 429-37. doi: 10.1016/j.psychres.2013. 11.019.

Robles, R. \& Páez, F. (2003). Estudio sobre la traducción al español y las propiedades psicométricas de las escalas de afecto positivo y negativo (PANAS). Salud Mental, 26(1), 69-75.

Rockliff, H., Gilbert, P., McEwan, K., Lightman, S., \& Glover, D. (2008). A pilot exploration of heart rate variability and salivary cortisol responses to compassion-focused imagery. Clinical Neuropsychiatry, 5, 132-139.

Scheel, C. N., Bender, C., Tuschen-Caffier, B., Brodführer, A., Matthies, S., Hermann, C., ... Jacob, G. A. (2014). Do patients with different mental disorders show specific aspects of shame? Psychiatry Research, 220(1-2): 490-5. doi: 10.1016/j.psychres.2014.07.062.

Uhrig, M. K., Trautmann, N., Baumgärtner, U., Treede, R.-D., Henrich, F., Hiller, W., \& Marschall, S. (2016). Emotion elicitation: A comparison of pictures and films. Frontiers in Psychology, 7. doi: 10.3389/fpsyg.2016.00180.

Watson, D., Clark, L. A., \& Tellegen, A. (1988). Development and validation of brief measures of positive and negative affect: The PANAS Scales. Journal of Personality and Social Psychology, 47, 1063-1070.

World Medical Association (2013). Declaration of Helsinki: Ethical Principles for Medical Research Involving Human Subjects. JAMA, 310(20): 2191-2194. doi:10.1001/jama.2013. 281053. 